\title{
PEMANFAATAN PEGAS DAUN BEKAS SEBAGAI BAHAN PENGGANTI MATA POTONG (PUNCH) PADA ALAT BANTU PRODUKSI MASSAL (PRESS TOOLS)
}

\author{
Fatahul Arifin \\ Jurusan Teknik Mesin Politeknik Negeri Sriwijaya Palembang \\ Jalan Srijaya Negara, Palembang 30139 \\ Telp.(0711)353414 Fax. (0711)355918 \\ Email:farifinus@polisriwijaya.ac.id,fatahul_arifin@lycos.com \\ Wijianto \\ Jurusan Teknik Mesin, Fakultas Teknik Universitas Muhammadiyah Surakarta \\ Jl. A. Yani Tromol Pos I Pabelan Kartasura Sukoharjo \\ E-mail:wijianto@ums.ac.id
}

\begin{abstract}
ABSTRAK
Pengembangan teknologi di bidang material sangatlah pesat sekarang ini, hal ini terlihat dari banyaknya penggunaan material logam khususnya di industri produksi massal dengan spesifikasi tertentu, seperti baja tahan karat, baja karbon tinggi, dan baja perkakas. Pada industri kecil seperti pembuatan ring, panci, tutup botol, komponen kompor dan lain-lain sering menggunakan material tersebut sebagai bahan untuk membuat alat bantu yang disebut dengan Press Tools. Pada press tool ini banyak digunakan baja karbon tinggi atau baja perkakas sebagai mata potong (punch), tetapi seiring mahal dan sulitnya material-material tersebut membuat para pelaku industri kecil mengalami kerugian yang besar untuk pembuatan alat bantu produksi. Untuk itu melalui penelitian ini penulis mengadakan percobaan di laboratorium terhadap bahan pegas daun bekas. Percobaan dilakukan empat tahap pengujian yaitu uji komposisi, uji tarik, uji kekerasan, dan uji struktur mikro. Pada uji komposisi material pegas daun bekas mempunyai kadar 0,6627 \% Carbon (C), 0,7304\%, Mangan (Mn), 0.0240\% Belerang (S), 0,0257\% Phosphor (P). Kekuatan tarik pegas daun bekas adalah 1332,5 kg/mm². Kekerasan dilakukan dengan uji kekerasan Rockwell C maka hasil dari ujinya adalah 52.5 HRC. Pada uji struktur mikro terdapat unsur martensit dan austenit. Pada akhirnya hasil percobaan laboratorium dibandingkan dengan data yang ada pada literatur maka material pegas daun bekas ini dapat digunakan untuk bahan pengganti mata potong pada alat bantu produksi massal.
\end{abstract}

Kata Kunci: Pegas daun bekas, Mata potong, Press Tools

\section{PENDAHULUAN}

Sekarang ini banyak industri yang bergerak di bidang produksi massal menggunakan material logam yang berasal dari baja dengan spesifikasi tertentu seperti baja perkakas, baja tahan karat, dan baja karbon tinggi. Untuk pemilihan material itu dapat dilakukan dengan melihat dari sifat-sifat yang dimiliki oleh material tersebut, seperti keunggulan operasional. Oleh karena itu perlu suatu pengembangan material sebagai cara menentukan apakah struktur dan sifat-sifat material optimum agar dapat tercapai daya tahan maksimum. 
Pada industri kecil seperti pembuatan ring, panci, tutup botol, komponen kompor, dan lainlain banyak menggunakan alat bantu produksi yang disebut press tools. Pada alat bantu produsi ini terdapat dua bagian penting yaitu mata potong (punch) dan landasan (die). Baja perkakas dan baja karbon tinggi adalah bahan yang banyak dipakai untuk pembuatan punch. Ditinjau dari segi kualitas memang baja perkakas dan baja karbon tinggi sangat baik dipakai untuk pembuatan punch. tetapi harganya sangatlah mahal dan sulit didapat di pasaran. Oleh karena itu, para pelaku bisnis mencari bahan pengganti dengan biaya yang murah dan mempunyai sifatsifat yang hampir sama dengan baja perkakas.

Salah satu hal yang terpenting untuk pemilihan bahan pengganti ini adalah dengan meninjau dari struktur dan sifat-sifat material yang optimum supaya daya tahan keausan dan dapat diaplikasikan untuk berbagai kondisi operasional, untuk itu penulis memilih dan melakukan pengujian bahan pegas daun bekas sebagai bahan pengganti alat potong, dikarenakan bahan ini murah harganya, mudah didapat dan tak kalah pentingnya adalah pemanfaat kembali bahan yang sudah tidak bermanfaat menjadi bahan yang bernilai ekonomis yang tinggi.

Pengujian bahan pegas daun bekas ini dilakukan untuk mengetahui apakah bahan pegas daun ini layak untuk menjadi bahan pengganti baja perkakas pada alat bantu produksi massal baik itu ditinjau dari struktur mikro, maupun dari sifat mekanis bahan pegas daun bekas ini.

Adapun tujuan yang diharapkan dari pengujian ini adalah untuk mengetahui perubahan struktur mikro yang terjadi di setiap siklus perlakuan pada bahan pegas daun bekas dan mengetahui sifat mekanis dari bahan ini serta melakukan perbandingan guna memutuskan bahwa bahan pegas daun bekas ini memang layak untuk dijadikan bahan pengganti baja perkakas.

Dalam kaitannya dengan pengujian ini ada beberapa hal yang dapat menjadi rumusan masalah yaitu Apakah pegas daun bekas ini layak sebagai bahan alternatif pengganti alat potong pada alat bantu produksi massal atau tidak, untuk itu perlu dilakukan uji komposisi, uji tarik, uji kekerasan untuk mengetahui bahan pegas daun termasuk dalam jenis baja yang mana.

Hasil dari penelitian ini diharapkan dapat dimanfaatkan sebagai bahan acuan dalam pemilihan material pengganti baja perkakas dengan biaya yang murah dan mempunyai spesifikasi dan kualitas yang hampir sama dengan bahan standard, sehingga dapat membantu dunia industri kecil tanpa mempengaruhi kualitas dan kuantitas produk.

\section{TINJAUAN PUSTAKA Pengertian Press Tool}

Press Tool adalah peralatan yang mempunyai prinsip kerja penekanan dengan melakukan pemotongan dan pembentukkan. Peralatan ini digunakan untuk membuat produk secara massal dengan produk keluaran yang sama dalam waktu yang relatif singkat.

\section{Klasifikasi Press Tool}

Press Tool dapat diklasifikasikan menjadi beberapa macam menurut proses pengerjaan yang dilakukan pada landasan, yaitu: simple tool, compound tool dan progressive tool.

\section{A. Simple Tool}

Simple Tool adalah jenis dari press tool yang paling sederhana, dimana hanya terjadi satu proses pengerjaan dan satu station dalam satu alat. Pemakaian jenis simple tool ini mempunyai keuntungan dan kerugian.

Keuntungan simple tool:

1. Dapat melakukan proses pengerjaan tertentu dalam waktu yang singkat, karena konstruksinya sederhana.

2. Harga alat relatif murah.

Kerugian simple tool:

1. Hanya mampu melakukan proses-proses pengerjaan untuk produk yang sederhana sehingga untuk jenis pengerjaan yang rumit tidak dapat dilakukan oleh jenis press tool ini.

2. Proses pengerjaan yang dapat dilakukan hanya satu jenis saja. 


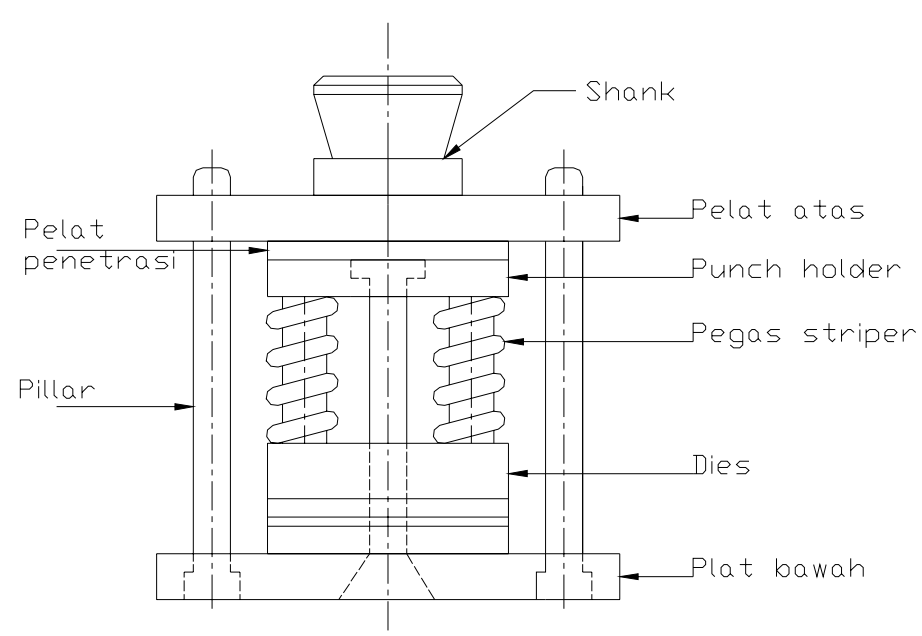

Gambar 1. Simple Tool

\section{Gambar 2. Compound Tool}

\section{B. Compound tool}

Pada press tool jenis ini, dalam satu penekanan pada satu station terdapat lebih dari satu pengerjaan, dimana proses pengerjaannya dilakukan secara serentak. Pemakaian jenis compound tool ini juga mempunyai keuntungan dan kerugian.

Keuntungan compound tool

1. Dapat melakukan beberapa proses pengerjaan dalam waktu yang bersamaan pada station yang sama.

2. Kerataan dan kepresisian dapat dicapai.

3. Hasil produksi yang dicapai mempunyai ukuran yang lebih teliti.
Kerugian compound tool:

1. Konstruksi landasan menjadi lebih rumit.

2. Terlalu sulit untuk mengerjakan material yang tebal.

3. Dengan beberapa proses pengerjaan dalam satu station menyebabkan perkakas cepat rusak.

\section{Progressive Tool}

Progressive Tool merupakan peralatan tekan yang menggabungkan sejumlah operasi pemotongan atau pembentukkan lembaran logam pada dua atau lebih station kerja, selama setiap langkah kerja membentuk suatu produk jadi. 


\section{Gambar 3. Progressive Tool}
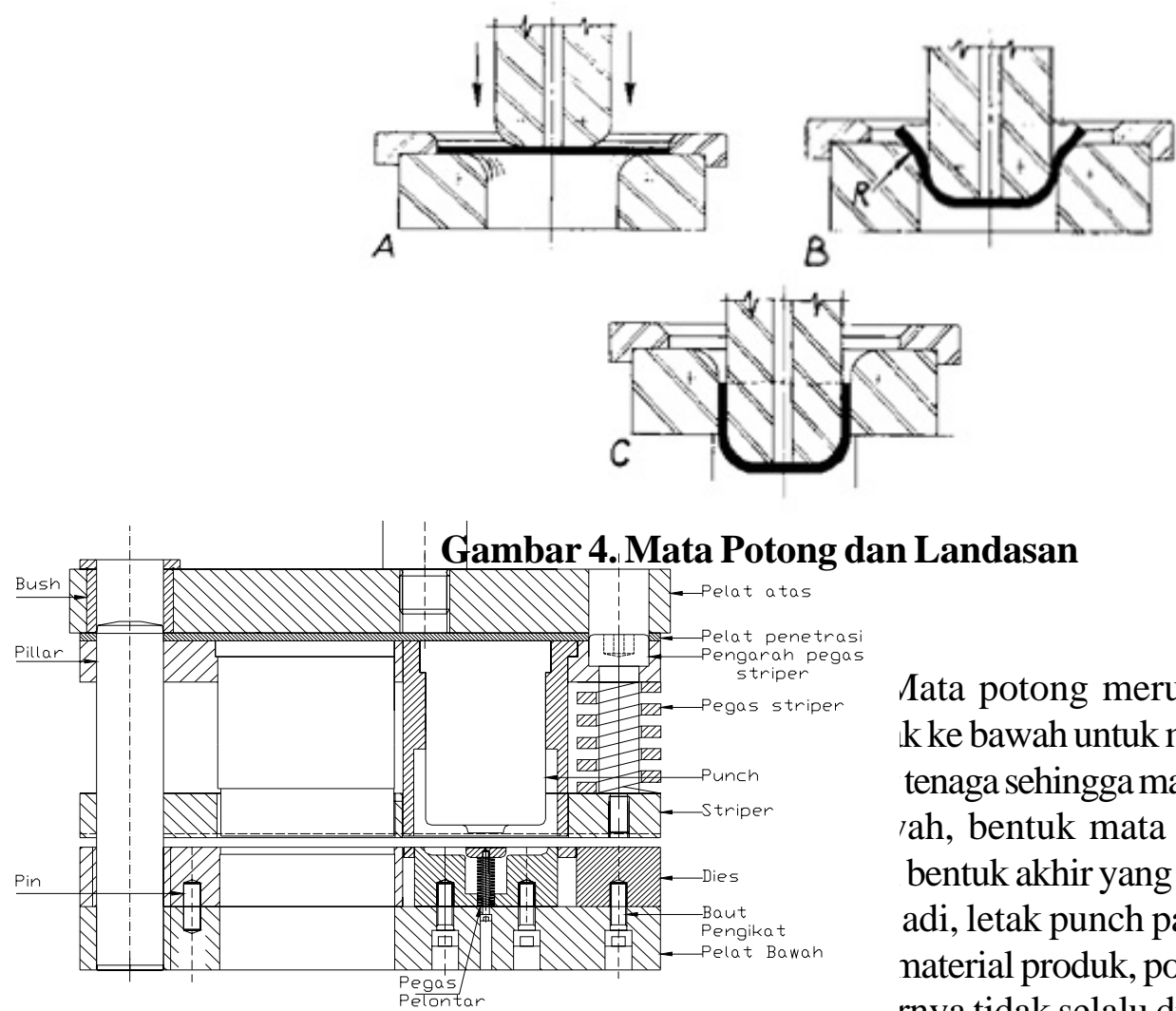

Mata potong merupakan bagian yang k ke bawah untuk meneruskan gaya dari tenaga sehingga material produk tertekan rah, bentuk mata potong disesuaikan bentuk akhir yang diiginkan dari proses adi, letak punch pada gambar 2 berada naterial produk, posisi dari mata potong rnya tidak selalu diatas tergantung dari

1. Ukuran alat lebih besar bila dibandingkan simple tool dan compound tool.

2. Biaya perawatan besar.

3. Harga relatif lebih mahal karena bentuknya rumit

Semua proses yang terjadi pada Press Tool melibatkan dua komponen penting yaitu: mata potong dan landasan. jenis landasan yang digunakan. Bahan mata potong harus cukup keras, juga memiliki keuletan dan ketahanan terhadap pengaruh gesekan saat pembentukan, dan bahan yang biasa digunakan seperti amutit.

Landasan merupakan komponen utama yang berperan dalam menentukan bentuk akhir dari benda kerja, bentuk dan ukurannya bervariasi sesuai dengan bentuk akhir yang diinginkan, 
kontruksi landasan harus mampu menahan gerakan, gaya geser serta gaya mata potong. Pada landasan terdapat radius tertentu yang berfungsi mempermudah reduksi benda saat proses berlangsung, lebih jauh lagi dengan adanya jari-jari diharapkan tidak terjadi sobek pada material produk yang akan dibentuk.

\section{Jenis Baja Karbon}

Menurut komposisi kimianya baja karbon dapat klasifikasikan menjadi tiga yaitu; Baja karbon rendah dengan kadar karbon 0,05 \% 0,30\% C, sifatnya mudah ditempa dan mudah di kerjakan pada proses permesinan. Penggunaannya untuk komposisi 0,05 \% - 0,20 \% C biasanya untuk bodi mobil, bangunan, pipa, rantai, paku keeling, sekrup, paku dan komposisi karbon 0,20 \% - 0,30 \% C digunakan untuk roda gigi, poros, baut, jembatan, bangunan.

Baja karbon menengah dengan kadar karbon 0,30\% - 0,60\%, kekuatannya lebih tinggi dari pada baja karbon rendah. Sifatnya sulit untuk dibengkokkan, dilas, dipotong. Penggunaan untuk kadar karbon 0,30 \% - 0,40 \% untuk batang penghubung pada bagian automotif. Untuk kadar karbon 0,40 \% - 0,50 \% digunakan untuk rangka mobil, crankshafts, rails, ketel dan obeng. Untuk kadar karbon 0,50 \% - 0,60 $\%$ digunakan untuk palu dan eretan pada mesin.

Baja karbon tinggi baja ini untuk pembuatan baja perkakas. Sifatnya sulit dibengkokkan, dilas dan dipotong. Kandungan 0,60 $\%$ - 1,50 \% C, kegunaan untuk pembuatan obeng, palu tempa, meja pisau, rahang ragum, mata bor, alat potong, mata gergaji.

Baja paduan yang diklasifikasikan menurut kadar karbonnya dibagi menjadi: baja paduan rendah jika elemen paduannya d” $2,5 \%$, baja paduan sedang jika elemen paduannya 2,5-10 $\%$, baja paduan tinggi jika elemen paduannya > $10 \%$.Selain itu baja paduan dibagi menjadi dua golongan yaitu baja paduan khusus dan high speed steel (HSS). Baja Paduan Khusus yaitu baja jenis ini mengandung satu atau lebih logam-logam seperti nickel, chromium, manganese, molybdenum, tungsten dan vanadium. Dengan menambahkan logam tersebut ke dalam baja maka baja paduan tersebut akan merubah sifat-sifat mekanik dan kimianya seperti menjadi lebih keras, kuat dan ulet bila dibandingkan terhadap baja karbon.

HSS (Self Hardening Steel) yaitu baja yang kandungan karbon 0,70 \% - 1,50 \%. kegunaan baja ini untukmembuat alat-alat potong seperti mata bor, pahat bubut, dan pahat milling. Disebut HSS karena alat potong yang dibuat dengan material tersebut dapat dioperasikan dua kali lebih cepat dibanding dengan baja karbon. Sedangkan harga dari HSS besarnya dua sampai empat kali daripada karbon.

Baja Perkakas (Tool Steel), dan sifat-sifat yang harus dimiliki oleh baja perkakas adalah tahan pakai, tajam atau mudah diasah, tahan panas, kuat dan ulet.

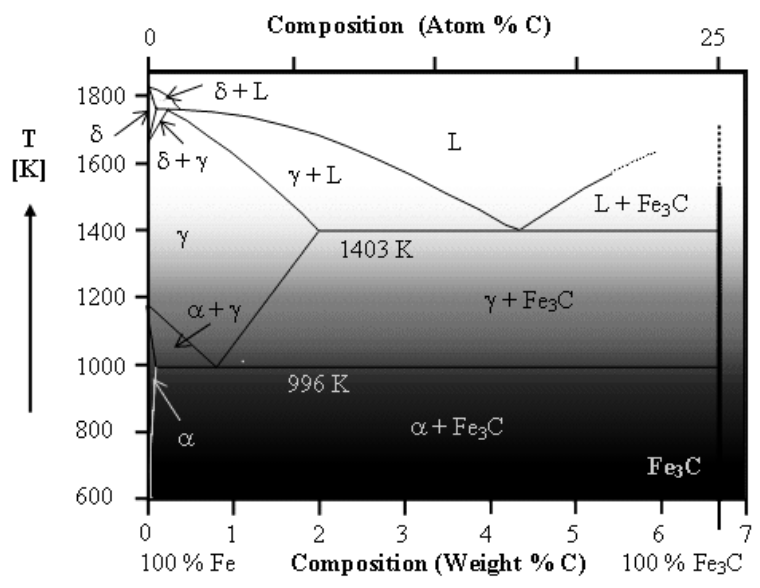

Keterangan : $\delta=$ ferit, struktur bcc

$\gamma=$ austenit, struktur fcc

$\alpha=$ ferit $\alpha$, struktur bcc

$\mathrm{Fe}_{3} \mathrm{C}=$ Sementit

\section{Gambar 5. Diagram Fase $\mathrm{Fe}_{-} \mathrm{Fe}_{3} \mathrm{C}$ (Structure Micro.Co.Id, 2007)}

\section{METODOLOGI PENELITIAN}

Pada penelitian ini material yang digunakan adalah pegas daun bekas yang ditemui dipasaran yaitu pasar barang bekas di Palembang. Untuk mengetahui komposisi dari pegas daun bekas dilakukan uji komposisi dan dicarikan literature yang sama yang menerangkan tentang jenis material yang mirip dengan pegas daun bekas. 


\section{Alat dan bahan}

Alat dan bahan yang digunakan dalam penelitian ini adalah:

- Sample pegas daun bekas yang ada di pasaran

- X-Ray Spectograf (alat uji komposisi)

- $\quad$ WP 310 Universal-Werkstoff-Prufgerat 50 $\mathrm{kN}$ (alat uji tarik)

- Universal Hardness Tester (Alat uji kekerasan)

- Mikroskop uji struktur mikro material logam

- Alat pengamplas dan polishing

- Bahan kimia yang digunakan DP-Spray dan larutan etsa (Oxalid acid)

\section{Persiapan Benda Uji}

a. Persiapan benda uji untuk uji komposisi Uji komposisi dilakukan pada pegas daun bekas, yaitu dengan jalan memotong material yang dibeli di pasaran dengan ukuran panjang $40 \mathrm{~mm}$ dan lebar $40 \mathrm{~mm}$ seperti pada gambar 6. Kemudian di haluskan bagian yang diuji.

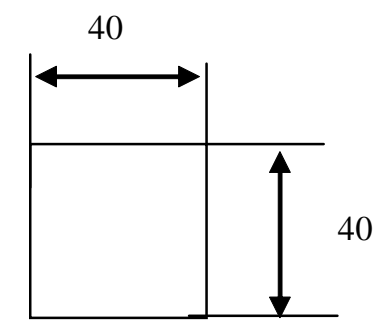

Gambar 6. Benda Uji untuk Uji Komposisi b. Persiapan benda uji untuk uji tarik material seperti pada gambar 7 .

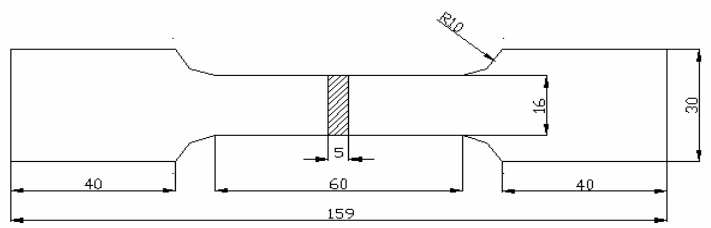

\section{Gambar 7. Benda Uji untuk Uji Tarik}

c. Persiapan benda uji untuk uji kekerasan Benda uji kekerasan diambil dari material langsung dari bahan uji.

d. Persiapan benda uji untuk uji struktur mikro Dalam pembuatan material uji struktur mikro ini hendaknya material dipotong dengan memperhatikan temperatur agar struktur mikro di dalam benda uji tidak berubah pada saat dilakukan pemotongan. Setelah itu benda uji di celupkan ke dalam larutan etsa yang telah disiapkan.

\section{DATA DAN ANALISA PENELITIAN}

\section{A. Pengujian Komposisi}

Pengujian komposisi dilakukan untuk mengetahui kandungan unsur kimia yang terdapat dalam benda/material uji. Dalam pengujian ini alat yang digunakan adalah Thermo ARL (Applied Research Laboratories) Type3560 Des. Hasil yang diperoleh dari pengujian material dapat dilihat pada tabel berikut.

Tabel 1. Hasil Pengujian Komposisi.

\begin{tabular}{lllllllll}
\hline No. & C & Mn & P & S & Cu & Ni & Mo & Fe \\
\hline 1. & 0,6650 & 0,7352 & 0,0253 & 0,0242 & 0,0964 & 0,0399 & 0,0014 & 97.3947 \\
2. & 0,6603 & 0,7255 & 0,0262 & 0,0238 & 0,0965 & 0,0404 & 0,0012 & 97.4202 \\
Jumlah & 1,3253 & 1,4607 & 0,0515 & 0,0480 & 0,1929 & 0,0813 & 0,0026 & 194.815 \\
Rata-rata & 0,6657 & 0,7304 & 0,0257 & 0,0240 & 0,0964 & 0,0401 & 0,0013 & 97.4075 \\
\hline
\end{tabular}

Berdasarkan pengujian pada tabel 1, komposisi bahan bekas pegas daun yang telah diuji jika dibandingkan dengan standar yang ada, termasuk kedalam jenis Baja AISI 1064 menurut standar Amerika (ASTM) yaitu baja karbon tinggi. 


\section{B. Pengujian Tarik}

Pengujian tarik dilakukan sebanyak 2 kali benda uji yang hasil percobaan terlihat seperti pada Tabel 3.

Tabel 3. Hasil Pengujian Tarik

\begin{tabular}{cccc}
\hline & \multicolumn{3}{c}{ Specimen } \\
\cline { 2 - 4 } & $\mathbf{1}$ & $\mathbf{2}$ & Rata-Rata \\
\hline Kekuatan & & & \\
Tarik & 1307,86 & 1357,14 & 1332,5 \\
$\left(\mathrm{~N} / \mathrm{mm}^{2}\right)$ & & & \\
\hline
\end{tabular}

\section{Pengujian Kekerasan}

Dalam pengujian ini menggunakan satu spesmen uji, pengujian di lakukan pada 5 titik. Pengujian kekerasan ini menggunakan pengujian Rockwell C.

Tabel 4. Hasil Pengujian Kekerasan Rockwell C

\begin{tabular}{|c|c|c|c|c|}
\hline No & $\begin{array}{c}\text { Tingkat } \\
\text { Kekerasan } \\
\left(\mathrm{kg} / \mathrm{mm}^{2}\right)\end{array}$ & Indentor & $\begin{array}{c}\text { Waktu } \\
\text { (s) }\end{array}$ & $\begin{array}{c}\text { Beban } \\
\text { (kg) }\end{array}$ \\
\hline 1 & 48.5 & Kerucut intan & 15 & 100 \\
\hline 2 & 55.5 & Kerucut intan & 15 & 100 \\
\hline 3 & 56.5 & Kerucut intan & 15 & 100 \\
\hline 4 & 54.5 & Kerucut intan & 15 & 100 \\
\hline
\end{tabular}

Dari tabel 4 maka dapat ditentukan bahwa tingkat kekerasan material berdasarkan pengujian Rockwell berkisar antara 48,5-56,5 HRC.

\section{Pengujian Metallography}

Pengujian ini dilakukan untuk melihat struktur mikro pada logam pegas daun bekas.

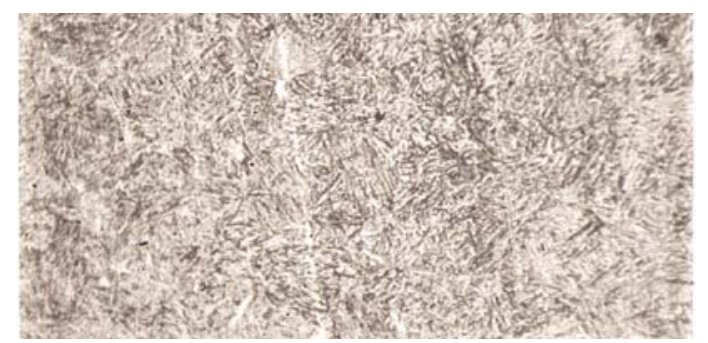

\section{Gambar 8. Struktur Mikro Material Pegas} Daun Bekas dengan Pembesaran 400X

Pada gambar 8 terlihat jelas adanya unsur martensit dan autenit yang membuat pegas daun bekas ini keras dan tangguh.

\section{KESIMPULAN}

Dari penjelasan diatas maka dapat disimpulkan bahwa material pegas daun bekas yang didapat di pasaran ini mempunyai komposisi 0,6627 \% Carbon (C), 0,7304\% Mange (Mn), 0.0240\% Belerang (S), 0,0257\% Phosphor (P), dan baja ini merupakan baja karbon tinggi bila menurut ASTM adalah AISI 1064 dengan kekuatan tarik 1332,5 N/mm². Dari pengujian kekerasan didapat bahwa material ini mempunyai tingkat kekerasan Rockwell 48,5 - 56.5 HRC. Setelah dilihat dari struktur mikro pada bahan bekas pegas daun ini mengandung martensit dan austenit. Dan bila dilihat dari semua data diatas maka bahan bekas pegas daun ini dapat direkomendasikan sebagai material pengganti mata potong.

\section{DAFTAR PUSTAKA}

Alok Nayer. 2002. The Steel Handbook. Mc Graw-Hill, New York

Budiarto, SST. 2001. Press Tool 3. Politeknik Manufaktur Bandung, Bandung.

Budinski K. G. and Budinski M. K., 1999. Engineering Material Properties and Selection, $6^{\text {th }}$ ed., Prentice Hall, New Jersey

Callister, William D. 2003. Materials Science and Engineering an Introduction. Sixth Edition. Singapore: John Wiley \& Son, Inc. 
Lukens, Robert.P, 1982. Annual Book Of ASTM Standar Metallography II. USA ......, Standard AISI.

......, Standard ASSAB.

www.efunda.com diakses 15 Juli 2007

www.strukturmikro.co.id diakses 1 Juli 2007

www.stainless steel.com diakses 16 Juni 2007 